\title{
Virus respiratorios en lactantes con infecciones respiratorias altas y bajas
}

\author{
Zdenka Papic G. ${ }^{1}$ : Lorena Rodríguez $\mathrm{O}^{2}$; \\ Carmen Larrañaga $\mathrm{L}^{3}$; Luis $\mathrm{F}$. Avendaño $\mathrm{C}^{3}$ \\ Viral antigens in infants with upper and lower \\ respiratory tract infections
}

\begin{abstract}
Detection of respiratory sincitial virus, adenovirus and influenza A and B virus was carried out in ambulatory and hospitalized patients younger than two years old Two nasopharvngeal aspirates were obtained from 165 ambulatory infants presenting acute uoper or mild lower respiratory tract infections and from 361 infants hospitalized for severe acute lower respiratory tract infections, from june throughout november 1991. Indirect monoclonal immunofluorescent assav was used for specific diagnosis. Epidemics of respiratory sincitial and influenza $A$ virus infections were respectively demonstrated along winter and sprirg. Distribution of viral detections was sirrilar among outpatients with either upper or lower respiratory svmptoms: positive results were obtained in $36 \%$ and $34 \%$ of ambulatory and hoscitalized children respectively. Viral antigens were not found among a healthy control group. Both ambulatorv and hospitalized children populations could be successfuly used for epidemialogical surveillance of respiratory viral intections, bit the latter offer advantages in sample collection.
\end{abstract}

[Key words: Virus, respiratory tract infections, irrmunofluorescence, indırect.]

Las infecciones respiratorias constituyen un problema prioritario en salud pública. Numerosos indicadores epidemiológicos lo demuestran: son la causa más frecuente de consulta en los policlínicos pediátricos, de ausentismo escolar y de hospitalización. Representan la primera causa de mortalidad infantil en el período postnatal y algunos estudios señalan que las bronconeumonías constituyen $75 \%$ de todas las muertes por infección respiratoria aguda en los menores de un ano ${ }^{1-3}$.

Entre 70 y $90 \%$ de las infecciones respiratorias agudas son causadas por virus, entre ellos rinovirus, coronavirus, virus respiratorio sinci-

Trabajo financiado por Proyecto FONDECYT $91 / 1133$, realizado como parte del programa de atención a nivel primario de infecciones respiratorias agudas, Servicio de Salud Metropolitano Norte, 1991. Trabajo de ingteso a la Sociedad Chilena de Pediatría.

1. Servicio de Salud Metropolitano (SSM) Sut y Norte. Hospital Exequiel González Cortés.

2. Consultorio La Pincoya.

3. Departamento de Microbiología y Parasitología. Facultad de Medicina Norte, Universidad de Chile. cial (VRS), adenovirus (ADV), virus influenza A-B-C (FLU), parainfluenza $1-2-3^{2,4,5}$. Si bien todos ellos pueden producir una variedad de problemas clínicos, algunos adquieren especial importancia por su capacidad de inducir infec. ciones respiratorias graves, que a menudo requieren hospitalización.

Actualmente se dispone de numerosas técnicas rápidas de inmunodiagnóstico, cuya aplicabilidad al diagnóstico de infecciones respiratorias ha sido ampliamente demostrada en Chile como en otros países. En efecto, en Santiago y otras regiones del país el virus sincicial respiratorio es el principal agente etiológico de las infecciones respiratorias agudas bajas del lactante que requieren hospitalización. Este virus es altamente contagioso $y$ se disemina rápidamente en la comunidad durante las épocas frías, ocasionando brotes epidémicos todos los años. Otros virus, como adenovirus e influenza, se presentan en forma más esporádica e irregular ${ }^{6-8}$.

Hasta ahora se han estudiado predominante. mente pacientes hospitalizados por infecciones respiratorias bajas, los cuales representan una población seleccionada por su severidad ${ }^{\$-12}$. Dado que las infecciones virales respiratorias 
habitualmente se presentan en brotes epidémicos, su impacto podría detectarse también en pacientes ambulatorios, pero en Chile no hay informes de estudios de este tipo.

Nuestros objetivos fueron describir la prevalencia de virus respiratorios en pacientes ambulatorios con infecciones respiratorias agudas altas o bajas, comparándola con la de lactantes hospitalizados por infecciones bajas y la frecuencia con que se detectan los antígenos virales estudiados en niños asin tomáticos ambulatorios.

\section{Material y Método}

Se tomaron dos muestras de aspirado nasofaríngeo en días sucesivos a nifios menores de 2 años que consultaron por infección respiratoria aguda alta o baja, en el consultorio "La Pincoya" del Servicio Metropolitano Norte de Salud de la ciudad de Santiago, entre el 1 de junio y el 30 de noviembre de 1991. Se compararon con niños de igual edad ingresados por infección respiratoria baja al hospital de nin̂os "Roberto del Río", de la misma localidad. Las muestras recolectadas se tras ladaron en frio al labotatorio antes de una hora para su procesamiento.

Se consideraron con infección respratoria aguda alta los njños que sufrían resfrío común, faringitis $y$ tos alta (sin ruldos bronquiales), con o sin fiebre. Se consideraron afectados por infecciones bajas los pacientes que consultaron por bronquitis simple, obstructiva (SBO) y la bronconeumonía, caracterizadas respectivamente por estertores, sibilancias o crépitos. No se incluyeron los casos de laringitis aguda. Se confeccionó un grupo control, a partir del día 1 del mes de julio del mismo período, con pacientes que acudieron i control de niño sano al consulturio y no ten ían síntomas respiraterios al momento de la recolección de la muestra.

Los pacientes ambulatorios de infecciones respiratorias sometidos al estudio fueron elegidos al azar de la consulta espontánea a un médico tratante del consultorio, cuidando de incluir una proporción de casos semejante para conformar los grupos de infección respiratoria alta, baja $y$ de control. Asimismo ingresaron al estudio los pacientes admitidos por infecciones respiratorias agudas bajas a dos de las salas de la unjad de lactartes del hospital, en el mismo período de tiempo.

La identificación de los virus en el aspirado nasofaríngeo se hizo mediante inmunofluorescencia indirecta, de acuerdo a la técrica habitual ${ }^{6,8}$, emplcando anticuerpos monoclonales contra adenovirus, virus res" piratorio sincicial, virus parainfluenza 1 y 2 procedentes del Centro de Control de Enfermedades (CDC), de Atlanta, LUA; anticuerpos monoclonales antivirus influenza $A$ y $B$, que fueron proporcionados por el Dr. P. Poithier, de Dijon (Francia), $y$, finalmente, conjugzdo anțiratón comercial (SIGMA). Estos reactivos fueron titulados previamente con muestras de pacientes, para definir la dilución óptima.

El análisis estadístico se hizo mediante dócima de diferencia de proporciones.

\section{Resultados}

En el transcurso de los seis meses señalados se estudiaron 361 niños hoapitalizados, en los cuales se obtuvo $34 \%$ de identificaciones positivas, y 165 niños ambulatorios, de los que $36 \%$ dieron resultados positivos global. En el grupo control, de 85 niños menores de dos años, ambulatorios, las reacciones de inmunofluorescencia resultaron negativas para todos los virus in. vestigados.

Las identificaciones positivas de antígenos virales en pacientes ambulatorios $y$ hospitalizados mostraron un alza importante en los meses de invierno, para disminuir en septiembre y mostrar una nueva onda positiva en primavera. Esta curva estacional se describe en la figura 1. En la figura 2 se expresa el número de casos positivos en pacientes con infección respiratoria aguda alta y baja y en niños sanos. También se pueden observar las dos ondas descritas en la figura anterior, que acumen con frecuencia semejante en infecciones altas y bajas.

E] primer brote, en los meses de invierno, se debió a virus respiratorio sincicial; en cambio, el de los meses de octubre y noviembre fue causado por virus influenza $A$, tanto en enfermos ambulatorios como hospitalizados, como lo muestra la figura 3. Los adenovirus se detectaron en proporciones pequeñas pero permanentes.

En la tabla se dan detalles de la distribución de las identificaciones virales, como del número de pacientes ambulatorios y hospitalizados estudiados. Hubo coincidencia en los resultados de la primera y segunda muestra de aspirado nasofaríngeo en todos los casos ambulatorios.

\section{Comentario}

Este trabajo muestra que es factible la identifícación de infecciones respiratorias virales en pacientes ambulatorios, sea con fines de diagnóstico etiológico o vigilancia epidemiológica. La recomendación de tomar dos muestras en días sucesivos para aumentar el rendimiento de la inmunofluorescencia indirecta ${ }^{3,12}$ tiene inconvenientes en los consultorios, pues implica citar por segunda vez al paciente $y$ exigir doble esfuerzo a la organización administrativa para la recolección y traslado de muestras. En esta breve experiencia no se observaron diferencias entre la primera y la segunda muestras, por lo que parece más operativo recomendar sólo una, 


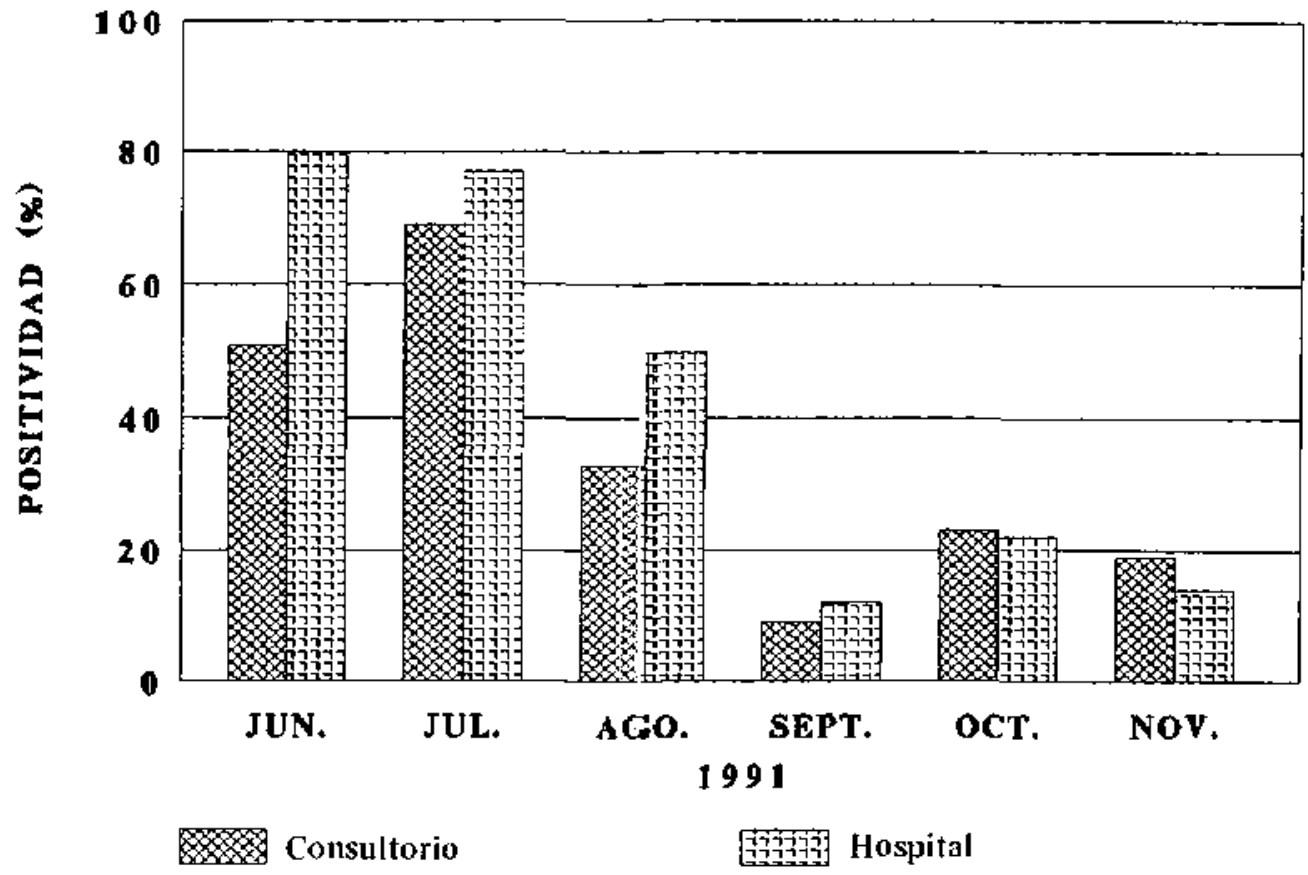

Figura 1: Detección de virus respiratorios en pacientes con IRA alta o baja. Distribución según condición de ambulatorio y hospitalizado. Santiago, junio noviembre 1991.

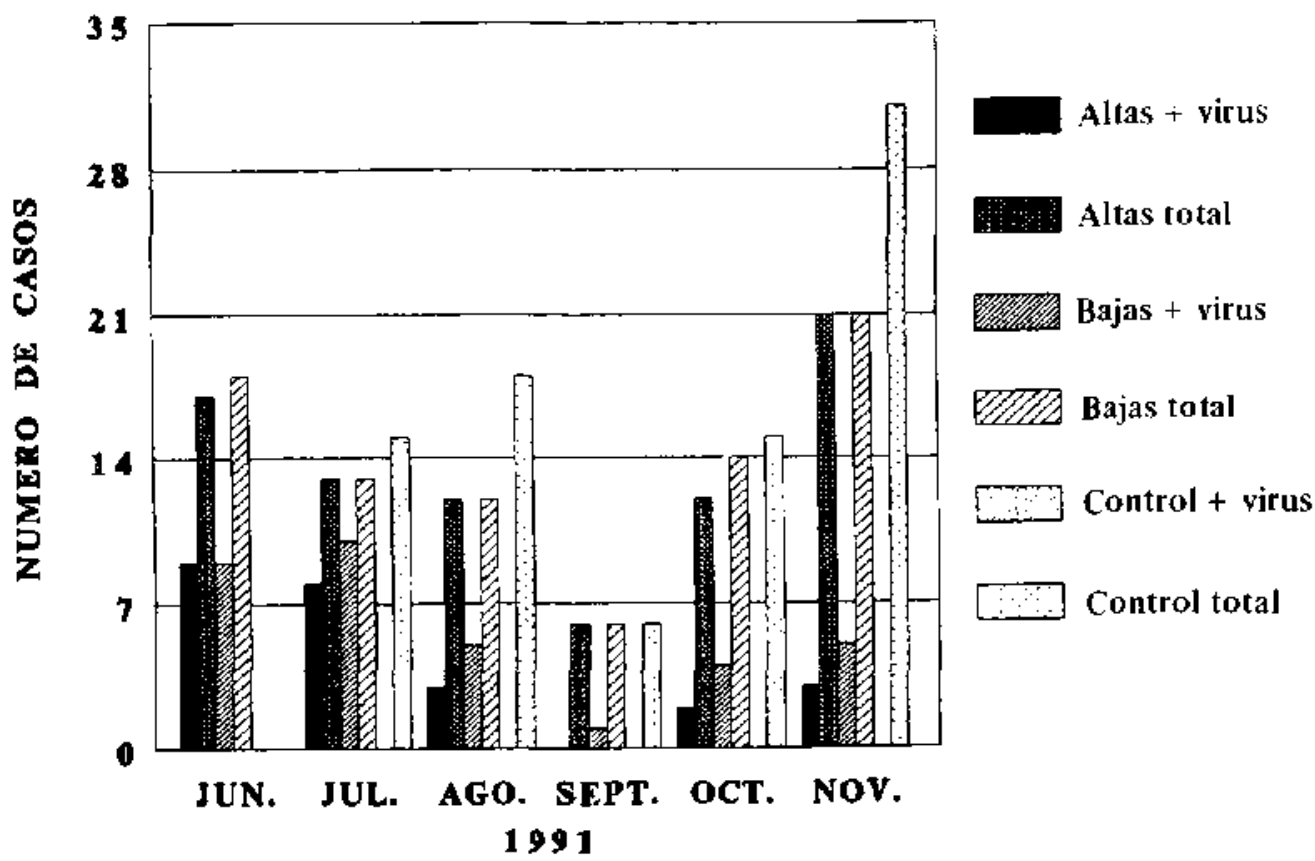

Figura 2: Detección de virus respiratorios en pacientes ambulatorios. Distribución según diagnóstico de IRA alta, baja y control. Consultorio Pincoya. Santiago, junio-noviembre 1991. 


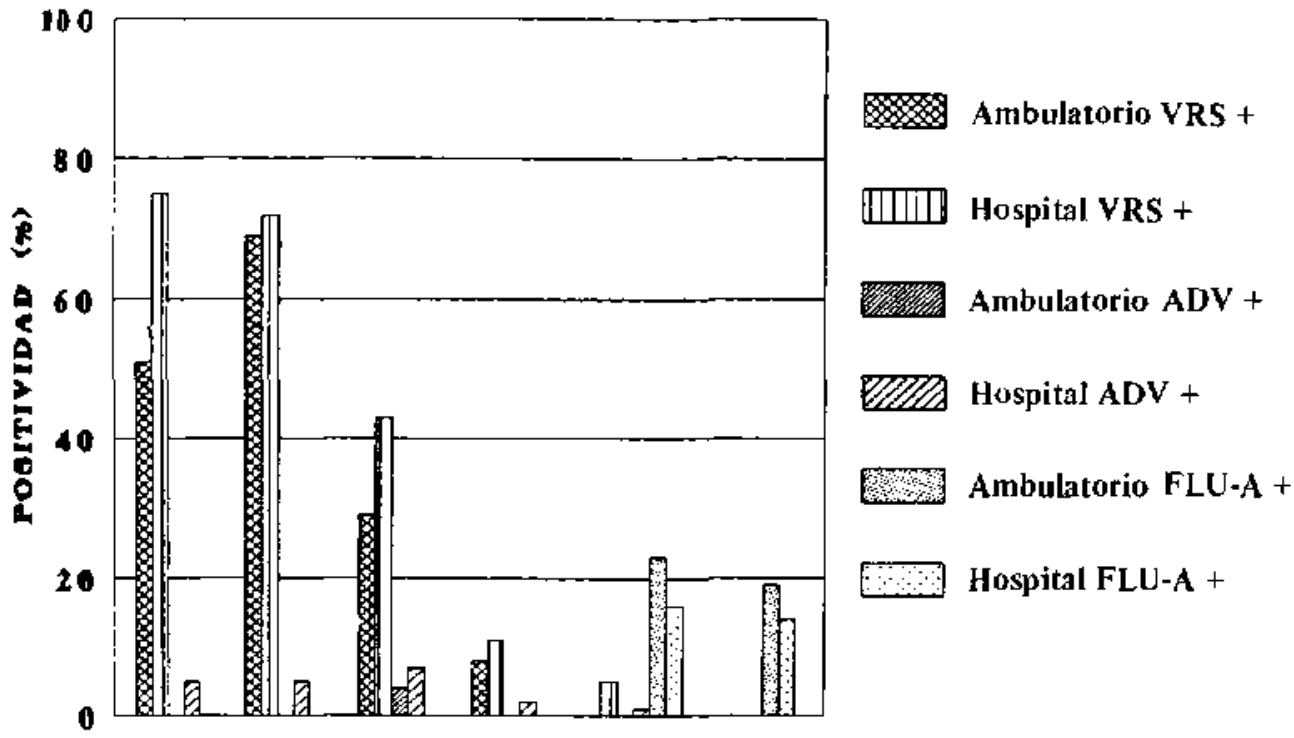

IUN. JUL. AGO. SEPT. OCT. NOV.

1991

Figura 3: Detección de virus respiratorios en pacientes ambulatorios y hospitalizados. Consultorio Pincoya y Hospital Roberto del Río. Santiago, junio-noviembre 1991.

\section{Tabla}

Detección de yirus respiratorios en nifros menores de dos años, ambulatorios y hospitalizados, con infección respiratoria aguda Santiago, junio a noviembre de 1991

\begin{tabular}{|c|c|c|c|c|c|c|c|}
\hline \multirow{3}{*}{ Mes } & & \multicolumn{3}{|c|}{ Ambulatorios } & \multicolumn{3}{|c|}{ Ho spitalizados } \\
\hline & & \multirow{2}{*}{$\begin{array}{c}\text { Casos } \\
\mathbf{n}\end{array}$} & \multicolumn{2}{|c|}{ Positivos } & \multirow{2}{*}{$\begin{array}{c}\text { Casos } \\
\mathbf{n}\end{array}$} & \multicolumn{2}{|c|}{ Positivos } \\
\hline & & & n & $\%$ & & $\mathbf{n}$ & $\%$ \\
\hline \multirow[t]{3}{*}{ Junio } & VRS & 35 & 18 & 51 & 20 & 15 & 75 \\
\hline & ADV & 35 & 0 & & 20 & 1 & 5 \\
\hline & FLU A & 35 & 0 & & 20 & 0 & \\
\hline \multirow[t]{3}{*}{ Julio } & VRS & 26 & 18 & 69 & 58 & 42 & 72 \\
\hline & ADV & 26 & 0 & & 58 & 3 & 5 \\
\hline & FLU A & 26 & 0 & & 58 & 0 & \\
\hline \multirow{3}{*}{ Agosto } & VRS & 24 & 7 & 29 & 30 & 13 & 43 \\
\hline & $\mathrm{ADV}$ & 24 & 1 & 4 & 30 & 2 & 7 \\
\hline & FLU A & 24 & 0 & & 30 & 0 & \\
\hline \multirow{3}{*}{ Septiembre } & VRS & 12 & 1 & 8 & 64 & 7 & 11 \\
\hline & ADV & 12 & 0 & & 64 & 1 & 2 \\
\hline & FLU A & 12 & 0 & & 64 & 0 & \\
\hline \multirow{3}{*}{ Octubre } & VRS & 26 & 0 & & 102 & 5 & 5 \\
\hline & $A D V$ & 26 & 0 & & 102 & 1 & 1 \\
\hline & FLU A & 26 & 6 & 23 & 102 & 16 & 16 \\
\hline \multirow[t]{3}{*}{ Noriembre } & VRS & 42 & 0 & & 87 & 0 & \\
\hline & ADV & 42 & 0 & & 87 & 6 & \\
\hline & FLU A & 42 & 8 & 19 & 87 & 12 & 14 \\
\hline Total & & 165 & 59 & 36 & 361 & 124 & 34 \\
\hline
\end{tabular}

Nota: No se detectó virus parainfluenza. Sólo se detectaron $2 / 64$ (3\%) casos de influenza $B$ en pacientes hospitalidos en septiembre. 
asumiendo el riesgo de disminuir en algo la sensibilidad del procedjmiento de detección.

Los resultados en pacientes ambulatorios fueron semejartes a los hospitalarios. Las infecciones virales respiratorias provocan enfermedades de diferente nagnitud, desde casos leves o asintomáticos hasta otros graves que pueden dejar secuelas o provocar muerte. Sólo los pacientes más graves requerirán hospitalización, por lo que los estudios basados en enfermos admitidos al hospital tienen el sesgo de representar poblaciones seleccionadas por su mayor severidad. Sin embargo, las condiciones para recolección de muestra son mejores en el hospital que en consultorios, es más fácil el acceso al paciente, el personal está mejor entrenado y son mayores las facilidades de conservación y traslado de muestras, entre otras. Si bien ciertos virus producen predominantemente infecciones leves. como en el caso de los rinovirus, los que más interesan por su capacidad patógena - virus sincicial, adenovirus, virus influenza y parainfluenza- pueden cursar con diferentes formas clínicas durante un brote epidémico, algunas de las cuales, seguramente una minoría, llegarán al hospital. De este modo, el estudio de los casos hospitalizados permitirá medir en forma indirecta la intensidad y duración de las infecciones virales capaces de provocar cuadros graves, aun cuando su impacto pudiera ser más masivo aún en la comunidad.

Como se ha demostrado en investigaciones anteriores, el virus sincicial respiratorio causa regularmente brotes en los meses frios y se asocia tanto a sintomas respiratorios altos, bajos, leves $y$ severos $^{2}$. El virus influenza $A$ se presentó como brote epidémico en la primavera del año 1991, ocasionando también diferentes cuadros clínicos, pero el bajo número de casos detectados no permite hacer un mejor análisis de los aspectos clínicos. También se pudo detectar otros vinus respiratorios en menor frecuencia, como ADV e influenza B, lo que demuestra que e] sistema diagnóstico implementado fue suficientemente sensible.

Llama la atención que en todos los controles sanos se obtuvieran resultados negativos, incluso en los períodos de mayor detección viral, ya que estudios previos ciue emplearon como controles a pacientes hospitalizados para cirugía electiva, supuestamente sin enfermedades infecciosas, mostraton porcentajes de positividad de alrededor de $10 \%{ }^{11}$. La diferencia pudiese ser ex- plicable tanto por la exigencia de que nuestros controles fuesen estrictamente asintomáticos, como la falta de oportunidad para adquirir infecciones cruzadas, mas propia de sujetos ambulatorios. En todo casu es posible que la forma de los estudios -selección de pacientes, técnica diagnóstica, número de muestras y otras características - afecte las opciones de detectar casos de excreción viral asintomática.

\section{Resumen}

Se buscaron antigenos de virus respiratorio sincicial, adenovirus y virus influenza $A$ y $B$ en lactantes menores de dos años ambulatorios y hospitalizados. Se tomaron dos muestras de aspirado nasofaríngeo a 165 lactantes ambulatorios con infección respiratoria aguda (IRA) alta o baja leve y a 361 hospitalizados por IRA baja severa, entre junio y noviembre de 1991, para reacciones de inmunofluorescencia indirecta. Se detectó un brote de infecciones por virus sincicial durante el invierno $y$ de influenza $A$ en primavera. No hubo diferencias significativas en la detección de virus respiratorio sincicial entre pacientes con infecciones altas o bajas ambulatorias: las proporciones de identificaciones positivas fueron $36 \%$ en pacientes ambula. torios y $34 \%$ en hospitalizados. No se detectaron virus en niños ambulatorios asintomáticos que acudian a control de sanos. La vigilancia epidemiológica puede hacerse a nivel ambulatoro u hospitalario, pero la última podría tener ventajas por ofrecer más facilidades para tomar y procesar las muestras.

(Palabras claves: Infección respiratoria viral, virus sincicial respiratorio, adenovirus, virus influenza, virus parainfluenza, inmunofluorescencia indirecta, vigilancia epidemiológica.)

\section{Agradecimientos}

Se ayradede a lnés Orellana y María Inés Fspinoza, por su excelente colaboración técrica, y al Dr. Eliecer villagra, por su asesor ía estadistica.

\section{Referencias}

1. Organización Panamericana de la Salud: Infecciones respiratorias agudas en los niños. Publicación Cient ífica No 493. Washington D.C., 1985.

2. Avendoño $l, F$ : Resfrío común, influenza y otras infecciones vúicas. Fin: Meneghello J. Fanta E. 
Paris E, Rossejot J, eds. Pediatría. Santiago. Pu. blicaciones Técnicas Mediterrăneo. 1991: 879. 883.

3. Koempfer AM, Medina E: Morbilidad y atención médica infantil en el Gran Santiago. Rev Chjl Pediatr 1980; $51: 355-369$.

4. Paisley $J W$, Latier $B A, M c I n t o s h ~ K$, Glode $M P$. Schahter $J$, Rumack $C$ : Pathogens associated with acute lower respiratory tract infection in young children. Pediatr Infect Dis 1984; 3: 14-19.

5. Téllez A, Pérez-Breña $P$, Fernández-Patiño $M V$, León $P$, Anda $P$, Nájera $R$ : Acute respiratory di sease in Spain: seven years of experience. Rev Infect Dis $1990 ; 12: 745-753$.

6. Farrot $R, \operatorname{Kim} H W$, Brandt $C D$ et al,: Respiratory Syncytial Virus, In: Lennette E, Schmidt $N$, eds. Diagnostic procedure for Viral, Rickettsial and Chlamydial Infections. Washington D.C.: American Public Health Association, 1979: 695-708.

7. Ahiuwalia G. Embree Y, McNicol P, Low B, Hammond $G W$ : Comparison of nasopharyngeal aspirates and nasopharyngeal swab specimens for Respiratory Syncytial Virus diagnosis by cell culture, indirect immunofluorescence assay and enzyme-linked immunosarbent assay. J Clin Microbiol 1987;25:763-767.

8. Larrañaga $C$, Avendaño $L F$, Gaggero $A$ ef al.: Diegnóstico de infección por adenovirus y virus sincicial respiratorio en lactantes: comparación entre aislamiento e inmunofluorescencia indirecta. Revista Chilena de Infectología (Santiago) 1990; 7: 167-171.

9. Vicente M, Wu E, Carrasco I, et al:- Participación viral en tas infecciones respiratorjas agudas bajas del lactante. Rev Chil Pediat 1 1988:59:353-357.

10. Soza G, Vicente $M$, Betancourt $M$ et al: Bronconeumonía del lactante menor. Correlación cínica, radiologica y etjología viral. Revista Chilena de Infectología (Santiago) 1987:4:82-86.

11. Escobar AM, Mortinez F, Ceruti $E$ et al.: Etiología de las infecciones agudas del tracto respiratorio bajo (IRAB) en lactantes hospitalizados: estudios virológicos. Rev Chil Pediatr 1988: 59: 349-353.

12. Avendaño LF, Larrañaga $C$, Palomino $M A$ et al.: Community and hospital acquired respiratory syncytial virus infections in Chile. Pediatr Infest Dis J 1991; 10: 564.568 . 